\title{
STUDI ANALISIS ANAK PUTUS SEKOLAH DI KECAMATAN JUNJUNG SIRIH KABUPATEN SOLOK
}

\author{
Rembulan $^{(1)}$, Afdhal $^{(2)}$ \\ Program Studi Pendidikan Geografi \\ Fakultas Ilmu Sosial, Universitas Negeri Padang \\ Email:Rembuland140896@gmail.com
}

\begin{abstract}
ABSTRAK
Penelitian ini bertujuan untuk mengetahui studi analisis anak putus sekolah di Kecamatan Junjung Sirih Kabupaten Solok. Jenis Penelitian ini adalah deskriptif dengan pendekatan kuantitatif. Populasi dalam penelitian ini adalah seluruh anak putus sekolah yaitu 1028 orang dengan jumlah sampel sebanyak 91 responden. Hasil penelitian ini menunjukkan bahwa: (1) faktor anak putus sekolah di Kecamatan Junjung Sirih yaitu faktor internal dan faktor eksternal. Faktor internal yang berasal dalam diri anak menunjukkan bahwa anak putus sekolah di Kecamatan Junjung Sirih Kabupaten Solok rata-rata berasal dari kemauan anak sendiri untuk berhenti sekolah. Faktor eksternal yaitu faktor yang berasal dari luar diri anak yang dilihat dari kurangnya perhatian orang tua terhadap anak, jarak rumah ke sekolah 1-3 Km, modal transportasi yang digunakan rata-rata memiliki kendaraan sendiri, tingkat pendidikan orang tua tergolong rendah, dimana tingkat pendidikan orang tua anak putus sekolah yaitu SD dan SMP, kondisi ekonomi orang tua yang tergolong rendah (miskin), dan pekerjaan orang tua anak juga rata-rata berprofesi sebagai petani dan nelayan, pendapatan yang diperoleh orang tua anak putus sekolah sekitar $\leq$ Rp.1500.000/bulan, tanggungan orang tua anak yang mengalami putus sekolah lebih $\leq 4$ orang. (2) Dampak yang ditimbulkan akibat anak putus sekolah di Kecamatan Junjung Sirih Kabupaten Solok yaitu kurangnya wawasan/ pengetahuan anak, menciptakan pengangguran, dan pernikahan dini.
\end{abstract}

Kata kunci : pendidikan, anak, putus sekolah, dampak

\section{ABSTRACT}

This research aims to determine the analysis study of school dropouts in Junjung Sirih District, Solok Regency. This type of research is descriptive with a quantitative approach. The population in this study were all school dropouts namely 1028 people with a total sample of 91 respondents. The results of this study indicate that: (1) factors dropping out of school in Junjung Sirih District are internal and external factors. Internal factors originating within the child show that dropping out of school in Junjung Sirih Sub district, Solok Regency, on average comes from the child's own willingness to quit school. External factors, namely factors originating from outside the child, seen from the lack of attention of parents to children, the distance from home to school 1-3 Km, transportation capital used on average have their own vehicles, the level of education of parents is low, where the level of education parents of out of school children namely elementary and junior high school, the economic condition of parents who are classified as low (poor), and the work of parents of children also on average work as farmers and fishermen, income earned by parents of out of school children is around $\leq R p .1500,000 /$ month, the dependents of parents of children who experience dropping out are more than 4 people. (2) The impact caused by children dropping out of school in Junjung Sirih District, Solok Regency is a lack of insight / knowledge of children, creating unemployment, and early marriage.

Keywords: education, children, dropping out of school ,impact

\footnotetext{
${ }^{1}$ Mahasiswa Program Studi Pendidikan Geografi Fakultas Ilmu Sosial

${ }^{2}$ Dosen Jurusan Geografi Fakultas Ilmu Sosial, Universitas Negeri Padang
} 


\section{PENDAHULUAN}

Putus sekolah adalah anak yang masih berusia sekolah yaitu usia 7-18 tahun yang dicatat sebagai peserta didik kemudian berhenti mengikuti program pendidikannya di sekolah sebelum menyelesaikan program pendidikan sekolah atau sebelum menamatkan studi dalam waktu yang ditetapkan. Menurut Trismansyah (1998) berpendapat bahwa anak putus sekolah ialah anak yang mengalami kegagalan dalam mengikuti pendidikan di sekolah, sehingga ia berhenti sekolah sebelum waktunya. Anak putus sekolah merupakan anak yang bersekolah di jenjang pendidikan Sekolah Dasar (SD), Sekolah Menengah Pertama (SMP) dan Sekolah Menengah Atas (SMA) tetapi belum menyelesaikan sekolahnya.

Menurut Imron (2004:) menyatakan yang dimaksud anak putus sekolah adalah anak yang telah dinyatakan telah keluar dari sekolah yang bersangkutan sebelum waktu yang telah ditentukan atau sebelum dinyatakan lulus dan mendapatkan ijazah dari sekolah.

Menurut Imron (2004), sebabsebab mengapa peserta didik drop out dan tidak menyelesaikan pendidikannya yaitu: 1) rendahnya kemampuan peserta didik, 2) tidak mempunyai biaya,3) sakit dan tidak tau kapan sembuh,4) bekerja membantu orang tua,5) kemauan untuk sekolah tidak ada, 6) terkena kasus pidana, 7) sekolah dianggap tidak menarik, sehingga anak tidak mau melanjutkan sekolah lagi.

Menurut Gunawan (2010), putus sekolah merupakan predikat yang diberikan kepada peserta didik yang tidak mampu menyelesaikan suatu jenjang pendidikan, sehingga tidak dapat melanjutkan studinya ke jenjang pendidikan selanjutnya. Misalnya seorang anak mengikuti jenjang pendidikan Sekolah Dasar (SD) sampai kelas 5 itu dinamakan putus sekolah, belum menyelesaikan tingkat pendidikan sekolah dasar (SD). Demikian juga seorang anak yang memiliki STTB SD ( tamat SD) kemudian melanjutkan ke jenjang pendidikan sekolah menengah pertama (SMP) sampai kelas 2 (dua) saja, disebut putus sekolah SMP begitu seterusnya.

Namun pada umumnya anak putus sekolah dipengaruhi oleh beberapa faktor seperti faktor ekonomi, perhatian orang tua, tanggungan keluarga, dan lingkungan keluarga. Menurut C.E Beeby (BP3K, 1981) menyatakan bahwa tidak mampu membiayai merupakan salah satu alasan utama anak putus sekolah, sebab umum yang kedua alasan anak putus sekolah yaitu kurangnya kesadaran orang tua terhadap pendidikan. Dimana semakin tinggi pendidikan orang tua anak, maka semakin tinggi pula kesadaran orang tua anak terhadap pendidikan anaknya. Begitu pula sebaliknya semakin rendah pendidikan orang tua anak, maka semakin rendah pula 
kesadaran orang tua terhadap pendidikan anaknya. (Putra, 2010)

Menurut BPS (2010) penyebab utama anak sampai mengalami putus sekolah adalah pendidikan orang tua rendah, menyebabkan kurangnya kesadaran orang tua akan pentingnya pendidikan anak, keterbatasan ekonomi/tidak ada biaya, keadaan geografis yang kurang menguntungkan, keterbatasan akses menuju ke sekolah, karena sekolah jauh atau minimnya fasilitas sekolah. Hal tersebut dapat mengakibatkan banyak anak putus sekolah yang di akibat dari beberapa faktor diatas.

Akibat dari anak putus sekolah sangat berdampak pada lingkungan masyarakat seperti pengangguran serta pernikahan dini di Kecamatan

Tabel 1. Data jumlah umur usia sekolah 7-18 Tahun di Kecamatan Junjung Sirih Kabupaten Solok.

\begin{tabular}{llccc}
\hline \multirow{2}{*}{ No } & \multirow{2}{*}{ Nagari } & \multicolumn{3}{c}{ Umur Usia Sekolah 7-18 Tahun } \\
\cline { 2 - 5 } & & $\mathbf{2 0 1 5}$ & $\mathbf{2 0 1 6}$ & $\mathbf{2 0 1 7}$ \\
\hline 1 & Muaro Pingai & 310orang & 369orang & 392orang \\
\hline 2 & Paninggahan & 2543orang & 2572orang & 2678orang \\
\hline Jumlah & 2853orang & 2941 orang & 3070orang \\
\hline
\end{tabular}

Sumber : Pengolahan Data Primer Kantor Camat Kecamatan Junjung Sirih, 2015-2017.

Data tabel di atas memperlihatkan bahwa jumlah anak berdasarkan umur usia sekolah dari usia 7-18 tahun pada tahun 2015 anak yang berusia 7-18 tahun berjumlah 2853 orang, pada tahun 2016 berjumlah 2941 orang dan pada tahun

Tabel 2. Jumlah murid yang sekolah di Kecmatan Junjung Sirih Kabupaten Solok

\begin{tabular}{llccc}
\hline \multirow{2}{*}{ No } & \multirow{2}{*}{ Nagari } & \multicolumn{3}{c}{ Jumlah Murid Yang Sekolah } \\
\cline { 2 - 5 } & Muaro Pingai & 2015 & $\mathbf{2 0 1 6}$ & $\mathbf{2 0 1 7}$ \\
\hline 2 & Paninggahan & 1989 orang & 273 orang & 270 orang \\
\hline \multicolumn{2}{l}{ Jumlah } & 2226 orang & 22030 orang & 1772 orang \\
\hline
\end{tabular}

2017 berjumlah 3070 orang. Dari data jumlah umur usia sekolah di Kecamatan Junjung Sirih diatas, maka peneliti juga dapat melihat jumlah anak yang sekolah pada tahun 2015 sampai 2017 sebagai berikut :
Junjung Sirih Kabupaten Solok. Anak perempuan putus sekolah di kecamatan ini memiliki kebiasaan menikah di usia muda yang mengakibatkan banyak anak-anak putus sekolah yang sudah menjadi orang tua. Sehingga permasalahan yang terjadi di Kecamatan Junjung Sirih Kabupaten Solok yaitu putus Jumlah anak putus sekolah di Kecamatan Junjung Sirih mengalami kenaikan dari data tahun 2015-2017. Berdasarkan hasil data kelompok yang sekolah pada tahun 2015 sampai 2017 diatas, maka dapat dilihat jumlah anak yang tidak bersekolah sebagai berikut. 
Sumber : Pengolahan Data Primer Kantor Camat Kecamatan Junjung Sirih

Berdasarkan data jumlah murid yang sekolah pada tahun 2015-2017, di Kecamatan Junjung Sirih pada tahun 2015 berjumlah 2226 siswa, pada tahun 2016 berjumlah 2207 siswa, dan pada tahun 2017 berjumlah 2042 siswa. Namun pada tabel kelompok usia seharusnya sekolah tidak sesuai dengan yang sekolah yang dilihat dari tahun 2015-2017. Oleh karena itu, maka dari data kelompok umur usia sekolah dengan data jumlah anak yang sekolah di Kecamatan Junjung Sirih dapat dilihat jumlah anak yang tidak bersekolah dari tahun 2015- 2017 sebagai berikut.

Tabel 3. Jumlah Anak Putus Sekolah di Kecamatan Junjung Sirih Kabupaten Solok

\begin{tabular}{llcccccc}
\hline \multirow{2}{*}{ No } & Nagari & \multicolumn{7}{c}{ Anak Putus Sekolah } \\
\cline { 3 - 8 } & & $\mathbf{2 0 1 5}$ & $\mathbf{\%}$ & $\mathbf{2 0 1 6}$ & $\mathbf{\%}$ & $\mathbf{2 0 1 7}$ & $\mathbf{\%}$ \\
\hline 1 & Muaro Pingai & 73 orang & $24 \%$ & 96 orang & $26 \%$ & 122 orang & $31 \%$ \\
\hline 2 & Paninggahan & 554 orang & $22 \%$ & 642 orang & $25 \%$ & 906 orang & $34 \%$ \\
\hline & Jumlah & 627 orang & $46 \%$ & 734 orang & $51 \%$ & 1028 orang & $65 \%$ \\
\hline
\end{tabular}

Sumber : Pengolahan Data Primer, 2019

Berdasarkan data jumlah anak putus sekolah pada rentang usia 7-18 tahun diatas, di Kecamatan Junjung Sirih pada tahun 2015 berjumlah 627 orang dengan persentase $46 \%$, jumlah anak putus sekolah pada tahun 2016 berjumlah 734 orang dengan persentase $51 \%$, dan jumlah anak putus sekolah tahun 2017 berjumlah 1028 orang dengan persentase $65 \%$. Hal ini dapat dilihat bahwa jumlah anak putus sekolah di Kecamatan Junjung Sirih setiap tahun mengalami kenaikan setiap tahun dari tahun 2015-2017.

\section{METODE PENELITIAN}

Jenis penelitian ini yaitu penelitian deskriptif kuantitatif. Populasi penelitian ini adalah seluruh anak yang mengalami putus sekolah yang berjumlah 1028 orang. Pemilihan sampel dilakukan dengan teknik simple random sampling, sehingga didapatkan sampel sebanyak 91 responden. Data penelitian ini meliputi anak putus sekolah yang dapat dilihat dari aktivitas anak putus sekolah, kemauan anak dalam melanjutkan pendidikan, namun penyebab anak putus sekolah dapat dilihat dari kondisi ekonomi orang tua, pendidikan orang tua, perhatian orang tua, tanggungan orang tua serta pendapatan orang tua. Teknik analisis data yang digunakan adalah persentase.

\section{HASIL DAN PEMBAHASAN Putus Sekolah}

Putus sekolah di Kecamatan Junjung sirih dapat dilihat tingkat anak mengalami putus sekolah , alasan anak putus sekolah, motivasi anak ketika masih sekolah, usaha yang dilakukan anak untuk 
melanjutkan pendidikan, tanggapan orang tua anak putus sekolah, usia putus sekolah, aktivitas anak yang mengalami putus sekolah.

\section{Tingkat Pendidikan Anak Putus Sekolah}

Tingkat pendidikan merupakan jenjang pendidikan yang terdiri dari jenjang pendidikan sekolah dasar (SD), sekolah menengah pertama (SMP), dan jenjang pendidikan sekolah menengah atas (SMA). tingkat pendidikan anak dalam penelitian ini meliputi dari tingkat berapa anak mengalami putus sekolah.

Tabel 4. Putus Sekolah Berdasarkan Tingkat Putus Sekolah Di Kecamatan Junjung Sirih Kabupaten Solok

\begin{tabular}{llrrrr}
\hline & & Frequency & Percent & Valid Percent & \multicolumn{2}{c}{$\begin{array}{c}\text { Cumulative } \\
\text { Percent }\end{array}$} \\
\hline \multirow{2}{*}{ Valid } & 38 & 41,8 & 41,8 & 41,8 \\
\cline { 2 - 6 } & SD & 30 & 33,0 & 33,0 & 74,7 \\
\cline { 2 - 6 } & SMP/MTs & 23 & 25,3 & 25,3 & 100,0 \\
\cline { 2 - 6 } & SMA/MA & 91 & 100,0 & 100,0 & \\
\cline { 2 - 6 } & Total & & &
\end{tabular}

Sumber: Pengolahan Data Primer, 2019.

Data tabel di atas memperlihatkan bahwa anak putus sekolah pada tingkat pendidikan SD berjumlah 38 orang dengan persentase $41,8 \%$, pada tingkat pendidikan SMP berjumlah 30 orang dengan persentase $33,0 \%$, dan anak putus sekolah pada tingkat pendidikan SMA berjumlah 23 orang dengan persentase 25,3\%. Jadi anak putus sekolah di tingkat pendidikan SD lebih banyak dibandingkan pada anak putus sekolah pada tingkat pendidikan SMP maupun SMA.

\section{Alasan Anak Putus Sekolah}

Alasan anak putus sekolah ini maksudnya adalah alasan apa yang membuat anak tidak mau melanjutkan pendidikannya. Alasan merupakan suatu proses penyampaian pemikiran dari jawaban pertanyaan.

Tabel 5. Alasan Anak Putus Sekolah di Kecamatan Junjung Sirih

\begin{tabular}{llrrrr|}
\hline & & Frequency & Percent & Valid Percent & \multicolumn{2}{c|}{$\begin{array}{c}\text { Cumulative } \\
\text { Percent }\end{array}$} \\
\hline \multirow{2}{*}{ Valid } & kurang minat belajar & 59 & 64,8 & 64,8 & 64,8 \\
\cline { 2 - 6 } & teman sebaya & 11 & 12,1 & 12,1 & 76,9 \\
\cline { 2 - 6 } & guru/sekolah & 8 & 8,8 & 8,8 & 85,7 \\
\cline { 2 - 6 } & ekonomi orang tua & 13 & 14,3 & 14,3 & 100,0 \\
\cline { 2 - 6 } & Total & 91 & 100,0 & 100,0 & \\
\hline
\end{tabular}

Sumber: Pengolahan Data Primer, 2019.

Dari tabel 5 menjelaskan bahwa, alasan responden yang kurang minat belajar berjumlah 59 orang dengan persentase $64,8 \%$, alasan karena teman sebaya berjumlah 11 orang dengan persentase $12,1 \%$, alasan karena malas dengan guru/ sekolah berjumlah 8 orang dengan 
persentase $8,8 \%$, dan alasan karena ekonomi orang tua berjumlah 13 orang dengan persentase 14,3\%. Namun alasan yang terbanyak di peroleh dari responden yaitu kurang minat belajar berjumlah 54 orang yaitu $59,34 \%$. Oleh sebab itu alasan anak putus sekolah di kecamatan junjung sirih rata-rata kurang minat anak dalam belajar/sekolah, sehingga anak tidak mau melanjutkan pendidikannya.

\section{Tanggapan orang tua anak putus sekolah}

Tanggapan orang tua disini maksudnya adalah bagaimana tanggapan orang tua anak yang mengalami putus sekolah. Tanggapan merupakan suatu pendapat ataupun reaksi seseorang yang di ungkapkan dengan penyampaian dalam menanggapi permasalahan.

Tabel 6. Tanggapan Orang Tua Anak Putus Sekolah di Kecamatan Junjung Sirih

\begin{tabular}{llrrrr}
\hline & & Frequency & Percent & Valid Percent & \multicolumn{2}{c}{$\begin{array}{c}\text { Cumulative } \\
\text { Percent }\end{array}$} \\
\hline \multirow{2}{*}{ Valid } & permintaan orang tua & 7 & 7,7 & 7,7 & 7,7 \\
\cline { 2 - 6 } & orang tua tidak setuju & 27 & 29,7 & 29,7 & 37,4 \\
\cline { 2 - 6 } & tidak masalah & 57 & 62,6 & 62,6 & 100,0 \\
\cline { 2 - 6 } & Total & 91 & 100,0 & 100,0 & \\
\hline
\end{tabular}

Sumber: Pengolahan Data Primer, di Kecamatan junjung Sirih tidak 2019.

Dari tabel 6 menyatakan bahwa, responden yang menyatakan bahwa tanggapan orang tua anak putus sekolah dari tanggapan permintaan orang tua sendiri berjumlah 7 orang dengan persentase $7,7 \%$, tanggapan orang tua yang menyatakan tidak setuju berjumlah 27 orang dengan persentase $29,7 \%$, sedangkan responden yang menyatakan tanggapan orang tua yang tidak masalah berjumlah 57 orang dengan persentase $62,6 \%$. Oleh sebab itu berdasarkan dari keterangan anak dan orang tua bahwa anaknya yang sudah berhenti sekolah tidak dipermasalahkan oleh orang tua ataupun keluarga, sehingga tanggapan orang tua terhadap anak putus sekolah masalah yaitu terdapat $62,63 \%$.

\section{Motivasi Anak Ketika Masih Sekolah Dan Usaha Untuk Melanjutkan Pendidikan Anak Putus Sekolah}

Motivasi ini maksudnya apakah ada motivasi anak ketika masih sekolah, jika anak memiliki motivasi yang bagus maka anak termaksud dengan anak memiliki kemauan dalam ilmu pendidikan, namun sebaliknya apabila anak tidak memiliki kemauan dalam pendidikan maka anak dikatakan sebagai anak yang tidak mempunyai motivasi ketika sekolah. Oleh sebab itu adapun usaha yang dilakukan untuk memotivasi anak yaitu dengan beberapa cara yang di anjurkan pemerintah untuk melanjutkan 
pendidikan yaitu dengan mengikuti paket.

Tabel 7. Motivasi Anak Ketika Masih Sekolah di Kecamatan Junjung Sirih

\begin{tabular}{llrrrr}
\hline & & Frequency & Percent & Valid Percent & \multicolumn{1}{c}{$\begin{array}{c}\text { Cumulative } \\
\text { Percent }\end{array}$} \\
\hline \multirow{2}{*}{ Valid } & Bagus & 15 & 16,5 & 16,5 & 16,5 \\
\cline { 2 - 6 } & tidak bagus & 76 & 83,5 & 83,5 & 100,0 \\
\cline { 2 - 6 } & Total & 91 & 100,0 & 100,0 & \\
\hline
\end{tabular}

Sumber: Pengolahan Data Primer, 2019.

Dari tabel diatas menyatakan bahwa, motivasi anak putus sekolah di Kecamatan Junjung Sirih tergolong tidak bagus. Sehingga usaha yang dilakukan anak putus sekolah untuk melanjutkan pendidikannya tidak ada.

Menurut Suasti (2018), perlunya pendidikan lingkungan bertujuan untuk mengembangkan kesadaran dan kepedulian terhadap masalah lingkungan yang memiliki pengetahuan, keterampilan, sikap, dan

komitmen untuk mencegahnya dengan mencari solusi untuk masalah

\section{Aktivitas Anak Putus Sekolah}

Aktivitas anak putus sekolah di sini maksudnya adalah apa saja aktivitas anak setelah putus sekolah. Berdasarkan hasil yang didapatkan di lapangan aktivitas anak yang mengalami putus sekolah banyak yang bekerja, membantu orang tua, pekerjaan rumah tangga dan ada yang pengangguran. Hal ini dapat dilihat dari hasil tabel dibawah ini:

Tabel 8. Aktivitas Anak Putus Sekolah Di Kecamatan Junjung Sirih

\begin{tabular}{llcccc}
\hline \multirow{2}{*}{ Valid } & Frequency & Percent & Valid Percent & $\begin{array}{c}\text { Cumulative } \\
\text { Percent }\end{array}$ \\
\cline { 2 - 6 } & Bekerja & 46 & 50,5 & 50,5 & 50,5 \\
\cline { 2 - 6 } & membantu orang tua & 19 & 20,9 & 20,9 & 71,4 \\
\cline { 2 - 6 } & RT & 6 & 6,6 & 6,6 & 78,0 \\
\cline { 2 - 6 } & pengangguran & 20 & 22,0 & 22,0 & 100,0 \\
\hline
\end{tabular}

Sumber: Pengolahan Data Primer, 2019.

Data diatas menyatakan bahwa Aktivitas bekerja berjumlah 46 orang dengan persentase $50,5 \%$, aktivitas membantu orang tua 19 orang dengan persentase 20,9\%, beraktivitas sebagai ibu rumah tangga berjumlah 6 orang dengan persentase 6,6\%, sedangkan yang tidak ada atau yang pengangguran berjumlah 20 orang dengan persentase $22,0 \%$. Jadi berdasarkan hasil yang di peroleh dari responden anak putus sekolah sekolah di Kecamatan Junjung Sirih yang paling banyak menjawab beraktivitas bekerja yaitu terdapat $50,5 \%$.

\section{Penyebab Anak Putus Sekolah}

Penyebab merupakan suatu faktor yang berdampak terhadap anak yang mengalami putus sekolah. Maka dari itu penyebab anak putus sekolah dapat dilihat dari : perhatian orang tua terhadap anak yang mengalami putus sekolah, jarak tempat tinggal ke 
sekolah, dengan apa anak berangkat ke sekolah, pendidikan orang tua, kondisi ekonomi orang tua, pendapatan orang tua dan tanggungan orang tua.

\section{Perhatian Orang Tua Ketika Masih Sekolah}

Perhatian orang tua di sini maksudnya bagaimana perhatian orang tua terhadap anak yang mengalami putus sekolah. Yang mana orang tua yang memiliki perhatian yang sangat cukup terhadap anaknya biasanya memiliki perhatian yang cukup pula terhadap pendidikan anaknya, begitu pula sebaliknya orang tua yang tidak perhatian terhadap anaknya maka orang tua anak tidak memiliki perhatian pula terhadap pendidikan anaknya. Hal ini sangat berkaitan dengan pendidikan anak yang mengalami putus sekolah.

Tabel 9. Perhatian Orang Tua Ketika Masih Sekolah di Kecamatan Junjung Sirih

\begin{tabular}{clccccc}
\hline \multirow{2}{*}{ Valid } & Frequency & Percent & Valid Percent & $\begin{array}{c}\text { Cumulative } \\
\text { Percent }\end{array}$ \\
\cline { 2 - 6 } & sangat memperhatikan & 1 & 1,1 & 1,1 & 1,1 \\
\cline { 2 - 6 } & cukup memperhatikan & 26 & 28,6 & 28,6 & 29,7 \\
\cline { 2 - 6 } kurang memperhatikan & 61 & 67,0 & 67,0 & 96,7 \\
\cline { 2 - 6 } & tidak memperhatikan & 3 & 3,3 & 3,3 & 100,0 \\
\cline { 2 - 6 } & Total & 91 & 100,0 & 100,0 & \\
\hline
\end{tabular}

Sumber : pengolahan data primer, 2019

Dari tabel diatas dapat dilihat bahwa, menyatakan orang tua kurang memperhatikan, yang mana responden yang menjawab orang tua kurang memperhatikan berjumlah 61 orang.

\section{Jarak Tempat Tinggal Ke} Sekolah

Tabel 10. Jarak Rumah Ke Sekolah di Kecamatan Junjung Sirih

\begin{tabular}{llr|r|r|r}
\hline & Frequency & Percent & Valid Percent & \multicolumn{1}{c}{$\begin{array}{c}\text { Cumulative } \\
\text { Percent }\end{array}$} \\
\hline Valid & $1-3 \mathrm{Km}$ & 86 & 94,5 & 94,5 & 94,5 \\
\cline { 2 - 6 } & $4-6 \mathrm{Km}$ & 4 & 4,4 & 4,4 & 98,9 \\
\cline { 2 - 6 } & $>6$ & 1 & 1,1 & 1,1 & 100,0 \\
\cline { 2 - 6 } & Total & 91 & 100,0 & 100,0 & \\
\hline
\end{tabular}

Sumber : pengolahan data primer, 2019

Tabel di atas terlihat bahwa, ratarata jarak rumah anak yang mengalami putus sekolah di
Jarak di sini maksudnya adalah berapa jauh tempat tinggal anak ke sekolah. Yang mana jarak sangat mempengaruhi pendidikan anak, oleh sebab itu perlu dibahas bagaimana jarak tempat tinggal anak yang mengalami putus sekolah ke sekolah. 
3. Tingkat pendidikan orang tua anak putus sekolah

Tingkat pendidikan orang tua di sini maksudnya adalah apakah pendidikan orang tua anak yang mengalami putus sekolah dapat mempengaruhi pendidikan anaknya, jika ia maka perlu dilihat pendidikan terakhir orang tua anak yang mengalami putus sekolah.

Tabel 11. Tingkat Pendidikan Terakhir Orang Tua Anak Putus Sekolah di Kecamatan Junjung Sirih.

\begin{tabular}{llrrrr|}
\hline & & Frequency & \multirow{2}{*}{ Percent } & Valid Percent & \multicolumn{2}{c|}{$\begin{array}{c}\text { Cumulative } \\
\text { Percent }\end{array}$} \\
\hline \multirow{3}{*}{ Valid } & SD & 32 & 35,2 & 35,2 & 35,2 \\
\cline { 2 - 6 } & SMP/MTs & 37 & 40,7 & 40,7 & 75,8 \\
\cline { 2 - 6 } & SMA/MA & 22 & 24,2 & 24,2 & 100,0 \\
\cline { 2 - 6 } & Total & 91 & 100,0 & 100,0 & \\
\hline
\end{tabular}

Sumber : pengolahan data primer, 2019.

Tabel 12 diatas terlihat bahwa, rata-rata pendidikan terakhir orang tuanya di tingkat pendidikan SMP, berdasarkan keterangan yang didapatkan dari responden anak yang mengalami putus sekolah rata-rata tidak mempengaruhi pendidikan anaknya. Dimana anak yang mengalami putus sekolah memang kemauan sendiri, dan orang tua anak yang mengalami putus sekolah pun tidak mempermasalahkan jika anaknya memilih berhenti sekolah. Ini menandakan bahwa belum adanya usaha maksimal dari orang tua untuk mengusahakan bagaimana anak mereka tetap melanjutkan pendidikannya.

4. Kondisi Ekonomi Orang Tua Anak Putus Sekolah Di Kecamatan Junjung Sirih

Kondisi ekonomi orang tua anak putus sekolah di sini maksudnya adalah bagaimana kondisi orang tua anak yang mengalami putus sekolah. Berikut gambaran kondisi orang tua dari anak-anak yang mengalami putus sekolah di Kecamatan Junjung Sirih yaitu sebagai berikut:

Tabel 12. Kondisi Ekonomi Orang Tua Anak Putus Sekolah di Kecamatan Junjung Sirih.

\begin{tabular}{lrr|r|r|r}
\hline & Frequency & Percent & Valid Percent & \multicolumn{2}{c}{$\begin{array}{c}\text { Cumulative } \\
\text { Percent }\end{array}$} \\
\hline \multirow{2}{*}{ Valid } & 1 & 1,1 & 1,1 & 1,1 \\
\cline { 2 - 6 } & & 9 & 9,9 & 9,9 & 11,0 \\
\cline { 2 - 6 } & tidak cukup & 41 & 45,1 & 45,1 & 56,0 \\
\cline { 2 - 6 } & kurang cukup & 40 & 44,0 & 44,0 & 100,0 \\
\cline { 2 - 6 } & cukup & 91 & 100,0 & 100,0 & \\
\cline { 2 - 6 } & Total & &
\end{tabular}

Sumber : pengolahan data primer, 2019. 
Dari tabel 12 di atas terlihat bahwa, kondisi ekonomi orang tuanya rata-rata tergolong miskin. Dimana anak yang mengalami putus sekolah memiliki ekonomi yang kurang cukup, sehingga anak memilih berhenti sekolah. Responden yang menyatakan kondisi ekonomi orang tua tergolong miskin berjumlah 41 orang dengan persentase $45,1 \%$.

\section{Pendapatan Orang Tua Anak Putus Sekolah}

pendapatan orang tua di sini maksudnya adalah berapa pendapatan orang tua anak yang mengalami putus sekolah, rata-rata orang tua anak putus sekolah memiliki pekerjaan sebagai petani.

Tabel 13. Pendapatan Orang Tua Anak Putus Sekolah di Kecamatan Junjung Sirih.

\begin{tabular}{llr|r|r|r}
\hline & Frequency & Percent & $\begin{array}{c}\text { Valid } \\
\text { Percent }\end{array}$ & $\begin{array}{c}\text { Cumulative } \\
\text { Percent }\end{array}$ \\
\hline Valid & $\begin{array}{l}\text { rendah < Rp.1500.000 } \\
\text { /bulan }\end{array}$ & 44 & 48,4 & 48,4 & 48,4 \\
\cline { 2 - 3 } & $\begin{array}{l}\text { sedang Rp. 1500.000- } \\
\text { 2500.000/bulan }\end{array}$ & 26 & 28,6 & 28,6 & 76,9 \\
$\begin{array}{l}\text { tinggi Rp. 2500.000- } \\
\text { 3500.000/bulan }\end{array}$ & 21 & 23,1 & 23,1 & 100,0 \\
\hline Total & 91 & 100,0 & 100,0 & \\
\hline
\end{tabular}

Sumber : pengolahan data primer, 2019.

Tabel 21 di atas terlihat bahwa, responden yang menyatakan orang tuanya bekerja sebagai petani berpendapatan sebanyak $<\mathrm{Rp}$. 1500.000/bulan.

\section{Tanggungan Orang Tua Anak Putus Sekolah}

Tanggungan orang tua di sini maksudnya, berapa orang yang masih ditanggung oleh orang tua anak yang mengalami putus sekolah. Dimana

Tabel 14. Tanggungan Orang Tua Anak Putus Sekolah di Kecamatan Junjung Sirih.

\begin{tabular}{llr|r|r|r}
\hline & Frequency & \multicolumn{1}{c}{ Percent } & Valid Percent & \multicolumn{2}{c}{$\begin{array}{c}\text { Cumulative } \\
\text { Percent }\end{array}$} \\
\hline \multirow{2}{*}{ Valid } & $<4$ & 76 & 83,5 & 83,5 & 83,5 \\
\cline { 2 - 6 } & $5-6$ & 14 & 15,4 & 15,4 & 98,9 \\
\cline { 2 - 6 } & $7-9$ & 1 & 1,1 & 1,1 & 100,0 \\
\hline
\end{tabular}

tanggungan orang tua juga dapat mempengaruhi pendidikan anak, yang mana jika tanggungan orang tua banyak kemungkinan besar tanggungan yang di keluarkan orang tua banyak pula, begitupun sebaliknya jika tanggungan orang tua sedikit maka pengeluaran orang tua sedikit pula. Oleh sebab itu perlu dibahas bagaimana tanggungan orang tua anak yang mengalami putus sekolah. 
\begin{tabular}{ll}
\hline Total & 91 \\
Sumber : pengolahan data primer,
\end{tabular} 2019.

Tabel di atas terlihat, yang diambil secara keseluruhan rata-rata tanggungan orang tua anak putus sekolah adalah $\leq 4$ orang. Yang mana jumlah tanggungan orang tua anak yang mengalami putus sekolah di kecamatan junjung sirih dibagi dengan jumlah responden untuk melihat rata-rata anak yang ditanggung dalam satu keluarga anak yang mengalami putus sekolah.

\section{KESIMPULAN}

1. Faktor internal, yaitu faktor yang berasal dari dalam diri anak. Berdasarkan pembahasan hasil penelitian diatas, maka dapat ditarik kesimpulan dari anak putus sekolah yaitu bahwa anak putus sekolah di Kecamatan Junjung Sirih Kabupaten Solok berhenti sekolah pada jenjang pendidikan Sekolah Dasar yaitu pada rentang usia 7-12 tahun, dengan alasan kurang berminat dalam belajar. Hal ini sangat mempengaruhi motivasi anak ketika dalam proses belajar, dimana motivasi anak ketika dalam proses belajar tidak bagus, sehingga usaha untuk melanjutkan pendidikan juga tidak ada. Oleh sebab itu tanggapan dari orang tua anak putus sekolah di Kecamatan Junjung Sirih Kabupaten Solok yaitu tidak masalah, yang

\section{$100,0 \quad 100,0$}

dikarenakan memang anak tidak ada minat untuk bersekolah. Sehingga aktivitas yang dilakukan anak putus sekolah di Kecamatan Junjung Sirih Kabupaten Solok yaitu bekerja.

2. Faktor eksternal yaitu faktor penyebab, yang berasal dari luar diri anak, faktor eksternal yang muncul sebagai penyebab anak putus sekolah di Kecamatan Junjung Sirih Kabupaten Solok yaitu : kurangnya perhatian orang tua terhadap anak yang dikarenakan sibuk dengan bekerja, jarak rumah anak ke sekolah rata-rata 1-3 Km, modal transportasi yang digunakan ratarata memiliki kendaraan sendiri, jadi jarak rumah anak ke sekolah tidak mempengaruhi pendidikan anak, dari tingkat pendidikan orang tua tergolong rendah, dimana pendidikan orang tua anak putus sekolah berpendidikan SD dan SMP, kondisi ekonomi orang tua yang tergolong rendah (miskin), dan pekerjaan orang tua anak juga rata-rata berprofesi sebagai petani dan nelayan, pendapatan yang diperoleh orang tua anak putus sekolah sekitar Rp. < Rp. 1500.000/per bulan, tanggungan orang tua anak yang mengalami putus sekolah lebih $\leq$ 4 orang.

3. Dampak anak putus sekolah di Kecamatan Junjung Sirih Kabupaten Solok putus sekolah 
pada anak yang disebabkan oleh faktor internal dan faktor eksternal menimbulkan dampak terhadap anak yang mengalami putus sekolah. Dampak yang ditimbulkan akibat anak putus sekolah di Kecamatan Junjung Sirih Kabupaten Solok yaitu kurangnya wawasan/ pengetahuan anak, menciptakan pengangguran, dan pernikahan dini.

\section{DAFTAR PUSAKA}

BP3K, YIIS. 1981. Pendidikan Di Indonesia. LP3ES: Jakarta.

BPS Kabupaten Solok, Kecamatan Junjung Sirih Dalam Angka. BPS Kabupaten Solok.

BPS. 2010. Statistik pendidikan 2009. BPS RI. Jakarta.

Gunawan, Ary. 2010. Sosiologi Pendidikan. Rineka Cipta: Jakarta.

Imron,Ali. 2004. Manajemen Peserta Didik Berbasis Sekolah. Department Pendidikan Nasional: Malang.

Pengolahan data Primer Kantor Camat Kecamatan Junjung Sirih, (2015-2017).

Putra, A. (2010). Penerapan Pembelajaran Kooperatif Model Group Investigation Pada Mata Pelajaran IPS Geografi. Laporan Penelitian Tindakan Kelas. Universitas Negeri Padang.

Suasti, Y., Barlian, E., Muchtar, B., Syah, N., \& Putra, A. (2018). Insert Religious Model in the
Construction Character of Care for the Environment to the Study of Geography in Padang City-Indonesia. Journal of Islamic Studies, 6(1), 67-70.

Trismansyah, (1998). Anak Putus Sekolah dan Permasalahannya. Jakarta: Rosda Karya. 